\title{
REPERTORIO BIBLIOGRÁFICO SOBRE LA CUESTIÓN CATALANA
}

\author{
ROSA M. ${ }^{a}$ FERNÁNDEZ RIVEIRA \\ Profesora Titular (A) Derecho Constitucional \\ Universidad Complutense de Madrid
}

\section{SUMARIO}

I. Introducción. II. Obras generales. III. Historia de Cataluña.

«... comparo el presente con el pasado y muestro cómo, al separar uno tras otro muchos hilos de un cable, éste ha acabado por romperse. Los principios de libertad en las ideas, de familiariedad con la soberana majestad, merecen la atención de aquel que intenta descifrar cuál ha sido la sucesión de ideas que ha originado una gran transformación en un Estado [...] la inestabilidad en los principios, y la torpeza, la debilidad y la ignorancia caracterizaron a la mayor parte de los ministros [...] Se contentaban con atender a las circunstancias no tenían planes ni propósitos, y no había ningún sentido de gobierno. La efervescencia de los ánimos incitaba a cambios constantes...»

SENAC DE MEILHAN, Dos interpretaciones de la Revolución Francesa

\section{INTRODUCCIÓN}

Este repertorio de bibliografía muestra un extenso número de obras sobre Cataluña; la recopilación se presenta con vocación histórica, política y jurídica. El protagonismo de Cataluña estos días es una evidencia y la necesidad de utilizar fuentes diversas y plurales para su reflexión y búsqueda de soluciones, una obligación.

En las siguientes páginas se citan libros monográficos, artículos científicos de revistas, textos jurídicos y políticos, recopilaciones de trabajos académicos debatidos en jornadas de reflexión, manifiestos, discursos, etc. Están en catalán y en castellano como requiere sin paliativos la materia que se reseña. Recorren un largo periodo de tiempo, el suficiente como para encontrar datos verdaderos, crí- 
ticas, opiniones plurales, testimonios suficientes y documentos que estuvieron o están en vigor y que son objeto de estudio.

Se enumeran con una sistemática expositiva que divide en dos grandes apartados todos los títulos: por un lado, obras generales y, por otro, reseñas ordenadas históricamente y de cuño político jurídico.

Este último bloque más extenso desde luego, está dividido a su vez en varios apartados. Y, desde la irrupción a finales del Siglo XIX de lo que ya en boca de Valentí Almirall constituyeron las primeras reivindicaciones del «catalanismo», hasta la moderna y vigente historia de Cataluña, todos las referencias tratan sus problemas y del devenir de sus días.

En primer lugar se documenta la etapa de la Restauración y las primeras reivindicaciones catalanas. Poco después, a principios del Siglo xx, se produjo la creación de la Mancomunidad como forma de organización que duró pocos años porque se impuso la dictadura de Primo de Rivera. A ella le sucedió la etapa republicana de 1931 con importantes cambios y un estatuto de autonomía en 1932 conocido como «el de Núria». El periodo republicano se vio bruscamente interrumpido por los «sucesos del 6 de octubre» y tan sólo dos años después la Guerra civil española volvió a cambiar el escenario y la realidad del pueblo catalán.

Seguidamente la dictadura franquista, la transición y el restablecimiento provisional de la autonomía fueron la antesala al Estatuto de Sau de 1979, que permitió un desarrollo autonómico bajo la Constitución del 1978 de casi tres décadas. Este camino culminó en el vigente y azaroso Estatuto de autonomía.

Y sin duda, los tres acontecimientos con personalidad propia en este último Siglo XXI son: el Estatuto catalán de 2006, la Sentencia del Tribunal Constitucional de 2010 y el convulso «proceso soberanista». Sobre ellos encontramos gran número de referencias bibliográficas de políticos, juristas, académicos, historiadores o investigadores que enriquecen el repertorio por la diversa naturaleza de sus contribuciones.

Constituyan todos estos títulos una herramienta útil a la altura de las necesidades.

\section{OBRAS GENERALES}

Agustí, D., Historia breve de Cataluña, Silex, Madrid, 2002.

Aja E., El Estado Autonómico. Federalismo y hechos diferenciales, Madrid, 2003.

Anglada, M. P., Historia de Cataluña, [s.1], [s.n], 2. vols., 1993.

Aubach, M. ${ }^{a}$ T. et alii, Cuatro estudios de la historia de Cataluña (siglos XIX y XX, Universidad Pontificia de Salamanca, Salamanca, 1988.

BALCElls, A., Cataluña contemporánea I. Siglo XIX, Siglo XXI, Madrid, 1984.

Cataluña contemporánea II. 1900-1939, Siglo XXI, Madrid, 1977.

Bel, Germà, Anatomía de un desencuentro. La Cataluña que es y la España que no pudo ser. Barcelona, Destino 2013. 
Borafull y Brocá, A., Historia crítica de Cataluña, 9 vols., Casset, Madrid, 1991.

Capdeferro, M., Otra historia de Cataluña, Acervo, Barcelona, 1985.

Carrera Pujal, J., Historia politica de Cataluña en el Siglo XIX, 7 vols., Ed. Bosch, Barcelona, 1967.

Casanova, E., Introducción a la historia de Cataluña, La Magrana, Barcelona, 1989.

CASSASAS, J., «Nación y nacionalismo: notas para el estudio comparado del caso catalán en relación al resto de nacionalismos periféricos de España», Universitat de Barcelona. Facultat de Geografia i Història. Departament d'Història Contemporània. Cercles: revista d'bistòria cultural (12): 8-25.

Cassese, A., Self-Determination of Peoples. A legal reappraisal. Cambridge University Pres 1995.

Caudet Yarza, F., Historia política de Cataluña, Producciones editoriales, 1978.

Claret, J.; Santirso, M. La construcción del catalanismo. Historia de un afán político. Madrid: Los Libros de la Catarata 2014.

Elias de Tejada, F. y Percopo, G., Historia del pensamiento político catalán, Montejura, 1963.

ENRIC J., «Modesta España». España en el diván. De la euforia a la desorientación, retrato de una década decisiva (2004-2014). Barcelona, 2014.

Esteva Fabregat, C. «La cuestión nacional catalana en la España contemporánea». Alteridades 7, pp. 47-48, 2014.

Fernández Riveira R., y GonZÁlez Hernández E., Cataluña en sus documentos, BOE, CEPC Colección Textos y Documentos n. 24, Madrid 2013.

García Venero, M., Historia del nacionalismo catalán, Editora Nacional, Madrid, 1944.

GonzÁlez Casanova, J. (Estudio introductorio), Textos Jurídics Catalans. Lleis i costums, vol. VI/I, Generalitat de Catalunya. Departament de Justicia, Barcelona, 1990.

Kleiner-Liebau Desiree, Migration and the Construction of National Identity in Spain, Ediciones Iberoaméricanas 15, 2009.

KNOP, K., Diversity and Self-Determination in International Law. Cambridge University Press 2002.

Llorens Ferrer, Marta (2013). «La Consulta popular como mecanismo para revitalizar el urbanismo democrático». Revista Catalana de Dret Públic (46).

Más TARrés, J., Breve historia de Cataluña basada en textos modernos, Publicaciones de Divulgación Histórica Catalana, Buenos Aires, 1970.

Muñoz Machado, S., Derecho público de las Comunidades Autónomas, Cívitas, Madrid 1982 (2. ${ }^{a}$ edición de 2007).

Cataluña y las demás Españas Crítica, 2014.

Nadal i Farreras, J. y WolfF, P. (dirs.), Historia de Cataluña, Oikos-tau, Barcelona, 1992.

Núñez Seixas, Xosé M., «Proyectos federales de los nacionalismos subestatales en España». Federalismo y cuestión federal en España, Universitat Jaume I, 2004.

Oliver Araujo, J. (Dr.), Balleter Cardell M. y Calafell Ferrá V. J., El Futuro Territorial del Estado Español. ¿Centralización, autonomía, federalismo, confederación o secesión?, Tirant lo Blanch, Valencia, 2014.

Pineda i Fargas, J., Breve historia de Cataluña basada en historias catalanas modernas, Biblioteca Catalana, México, 1957.

Reglá, J., Història de Catalunya, Alianza, Madrid, 4. ${ }^{a}$ ed., 1981.

UNED. Teoría y Realidad Constitucional, núm. 37, 2016, pp. 607-626 
Ruiz Rodríguez, S., La teoría del derecho de autodeterminación de los pueblos. Madrid: Centro de Estudios Políticos y Constitucionales 1998.

SAn Agustín, A., Cuando se jodió lo nuestro. Cataluña-España: crónica de un portazo. Barcelona: Península 2014.

Sobrequés, J., Historia contemporània de Catalunya, 2 vols. Columna, Barcelona, 1998.

Soldevilla, F., Síntesis de historia de Cataluña, Ediciones Destino, Barcelona, 1973.

Historia de Catalunya, Alpha, Barcelona, 1962.

Valls i Taberner, F. y Soldevila, F., Història de Catalunya, Publicaciones de l'Abadia

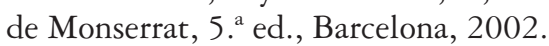

- Historia de Cataluña, Alianza Editorial, Madrid, 1982.

ViCens Vives, J., Cataluña en el Siglo XIX, Rialp, Madrid, 1961.

Vilar, P. y Termes, J. (coord.), Historia de Catalunya, 10 vols., Ediciones 62, Barcelona, 1987-2003.

\section{HISTORIA DE CATALUÑA}

\section{El «catalanismo» durante la Restauración}

Albertí, S., El republicanismo catalá i la Restauració monárquica, 1875-1923, Albertí, Barcelona, 1972.

Cамвó, F., Catalunya i la Solidaritat, Barcelona, 1910.

CARDONA, J., «La formación del imaginario histórico del nacionalismo catalán, de la Renaixença al Noucentisme (1830-1930)», Historia Contemporánea, n. ${ }^{\circ}$ 22, 2001.

Cassasas, J., Entre Escilla i Caribdis. El catalanisme i la Catalunya conservadora en la segonda meitat del segle XIX, La Magrana, Barcelona, 1990.

Coll i Amargós, J. y Llorens I Vila, J., Els quadres del primer catalanisme, 1882-1900, Edicions Catalanes de París, París, 1975.

Colomines, A., La política catalana a les Corts espanyoles: economia i descentralizació (18981917), Publications Universitat de Barcelona, Barcelona, 1993.

Les Bases de Manresa de 1892 i els origens del catalanisme, Generalitat de Catalunya, Barcelona, 1992.

Culla i Clarà, J. B., El republicanisme lerrouxista a Catalunya (1901-1923), Curial, Barcelona, 1986.

Ferré I TriLl, X., «Catalanismo republicano en la Cataluña del Siglo XIX (entre la historia cultural y la biografía política)», Studia Histórica. Historia contemporánea, n. ${ }^{\circ} 18$, 2000 .

González Casanova, J. A., Federalismo y autonomía: Cataluña y el Estado español, 18681938, Crítica, Barcelona, 1979.

Moliner Prada, A., «El catalanismo político y la regeneración de España», Trienio, n. ${ }^{\circ} 40$ (noviembre), 2002.

Pérez Francesch, J. L., Les Bases de Manresa i el programa politic de la Unió Catalanista 1891-1899, Bellaterra/Universitat Autónoma de Barcelona, Barcelona, 1987.

Riquer i Permanyer, B., Escolta, Espanya la cuestió catalana en la época liberal, Marcial Pons, Madrid, 2001. 
- El conservadorismo polític catalá: del fracàs del moderantisme al desencís de la Restauració, Barcelona, 1971.

SÁNCHEZ, A., Barcelona 1888-1929: Modernistas, anarchistes, noucentistes ou la création fiévreuse d'une nation catalane, Auttrement, París, 1992.

SÁNCHEZ GonZÁlez, J., «Topología discursiva del catalanismo en la Restauración: Cambó ante castellanos, vascos y catalanes», Historia contemporánea, n. . 28, 2004.

Tous, J., La forma del catalanisme polític a Reus: «Lo Somatent!», 1866-1903, Associació d'Estudis Reusencs, Reus, 1987.

Vilar, P., Cataluña en la España moderna, Crítica, Barcelona, 1978.

VV.AA., El Memorial de Grenges i el catalanisme polític, La Magrana, Barcelona, 1986.

\section{Las primeras reivindicaciones}

ANGuera, P., «Españolismo y catalanidad en la historiografía catalana decimonónica», Hispania: Revista Española de Historia, n. ${ }^{\circ}$ 209, vol. 61, 2001.

Anguera, P., Els precedents del catalanisme: catalanitat i anticentralisme: 1808-1868, Empúries, Barcelona, 2000.

Arbós, X., «Els antecedents histórics de l'autonomia de Catalunya», Dret Public de Catalunya, CEDECS, Barcelona, 2003.

Casassas YMBert, J. (Introducción y notas), Cataluña y la España plural: Discursos políticos del Siglo Xx. Selección de textos, Aurea, Barcelona, 2006.

Farnés, S. y Llorens, J., Articles catalanistas (1888-1891), Ediciones 62, Barcelona, 1982.

Ferrán Oliva, J. M., La Constitució catalana de l'Havana, Pagés, Lleida, 2005.

González Casanova, J., Federalismo y autonomía: Cataluña y el Estado español. 18681938, Crítica, Barcelona, 1979.

IZQUIERDO BALLESTER, S., La primera victòria del catalanisme politic: el triomf electoral de la candidatura dels «quatre presidents» (1901), Pòrtic, Barcelona, 2002.

Maura, A. et alii, La Autonomía Catalanista ante el Parlamento Nacional: Documentos históricos, ed. Unión Monárquica Nacional. Imprenta Editorial Barcelonesa, Barcelona, 1919.

Molas, I., «Las bases de Manresa y la reforma del Estado español», Revista Jurídica de Cataluña, n. ${ }^{\circ} 74,1970$.

Moliner Prada, A., «El catalanismo político y la regeneración de España», Trienio: Ilustración y liberalismo, n. ${ }^{\circ} 40,2000$.

\section{La «solución» de la Mancomunidad}

Balcells, A., El projecte d'autonomia de la Mancomunitat de Catalunya del 1919 i el seu context històric. Publicación Barcelona: Parlament de Catalunya, 2010.

Balcells, A.; Pujol, E. y Sabater, J., La mancomunitat de Catalunya i l'autonomia, Institut d'Estudis Catalans/Proa, Barcelona, 1996.

CAmps i Arboix, J. de., La Mancomunitat de Catalunya, Bruguera, Barcelona, 1968.

UNED. Teoría y Realidad Constitucional, núm. 37, 2016, pp. 607-626 


\section{La dictadura de Primo de Rivera}

Roig I Rosich, J. M., La Dictadura de Primo de Rivera a Catalunya. Un assaig de represió cultural, PAM, Barcelona, 1992.

Termes, J., Història del catalanisme fins el 1923, Pòrtic, Barcelona, 2000.

\section{La «cuestión catalana» en la II República, Pacto de San Sebastián y} proclamación de la República

Aguilera de Prat, C. R., «El catalanismo político ante la II República: entre el pragmatismo y el mito», Los nacionalismos en la España de la Segunda República, J. G. Beramendi y R. Maiz (comps.), Siglo xx en España, Madrid, 1991.

Alzina, J., L'autonomía de la Catalunya autónoma, Emporium, Barcelona, 1933.

Anguera Nolla, P., «La cuestión catalana en la Segunda República», Terceras Jornadas Niceto Alcala-Zamora y su época, Oriego (Córdoba) 3, 4 y 5 de abril de 1997, Córdoba, 1998.

Beramendi GonZÁlez, C. R., «Nacionalismos, regionalismo y autonomía en la Segunda República», Pasado y Memoria. Revista de Historia contemporánea, n. ${ }^{\circ}$ 2, 2003.

Duarte, Monserrat, Á., «Republicanos y nacionalismo: El impacto del catalanismo en la cultura política republicana», Historia Contemporánea, n. ${ }^{\circ}$ 10, 1993.

Fernández Almagro, M., Catalanismo y República española, Madrid, 1932.

González Casanova, J. A., Federalismo y autonomía. Cataluña y el Estado español 18681938, Grijalbo, Barcelona, 1979.

GonZÁlez i Vilalta, A., «La minoría catalana en las Cortes Constituyentes (19311933)», Ayer, n. ${ }^{\circ}$ 56, 2004.

Hernández Lafuente, A., Autonomía e integración en la Segunda República, Ed. Encuentro, Madrid, 1980.

Ortega y Gasset, J.; Azaña, M. y Ridao, J. M., Dos visiones de España: discursos en las Cortes Constituyentes sobre el Estatuto de Cataluña, Galaxia Gutenberg/Círculo de Lectores, Barcelona, 2005.

Orwell, G., Cataluña 1937: testimonio sobre la revolución española, Proyección, Buenos Aires, 1963.

PÉrez-Ayala, A., «Federalismo y autonomías. La organización territorial del Estado en el constitucionalismo republicano», El republicanismo español, Raíces históricas y perspectivas de futuro, Á. Egido León y M. Núñez Díaz-Balart (dirs.), Biblioteca Nueva, Madrid, 2001.

Roig i Rosich, J. M., L'Estatut de Catalunya a les Corts Constituents, 1932, Curial, Barcelona, 1978.

Rovira i Virgili, A., Catalunya i la República, Undarius, Barcelona, 1977.

SAguer y Olivet, E., La cuestión catalana y el Estatuto de Cataluña, Herederos de Serra y Rusell, Barcelona, 1931.

Soldevila, F., História de la proclamació de la Republica a Catalunya, Curial, Barcelona, 1977. 
Tornafoch, X., «Los debates del Estatuto de Autonomía de Cataluña en las Cortes republicanas (mayo-agosto de 1932): El idioma catalán y el sector escolar», Historia Actual Online, 2004

Tomás y Valiente, F., Soberanía y autonomía en la II República y en la Constitución de 1978, Departamento de Justicia de la Generalitat de Cataluña, Barcelona, 1996.

\section{El Estatuto de Nuria y el desarrollo de la autonomía}

Azaña, M., Sobre la autonomía política de Cataluña, Selección de textos y estudio preliminar de Eduardo García de Enterría, Tecnos, Madrid, 2005.

Azaña, M., Defensa de la autonomía de Cataluña, Undarius, Barcelona, 1977.

Camps i Arboix, J. de, El parlament de Catalunya (1932-1936), Ediciones 62, Barcelona, 1976.

Gerpe Landín, M., L'Estatut d'Autonomia de Catalunya i l'estat integral, Ediciones 62, Barcelona, 1977.

GonZÁlez Hernández, E., «La reforma estatutaria en la Constitución de 1931. Análisis de las previsiones del Estatuto de Nuria de 1932 y del Estatuto vasco de 1936», Reforma constitucional y reforma estatutaria. Vera Santos, J. M. y Díaz-Revorio, J. (coords.), La Ley, Madrid, 2009.

- «Catalogna.1932-2006: «L'operazione autonomía», Il Diritto della Regione, n. ${ }^{\circ} 3,2010$.

Gómez Orfanel, G., «La legislación catalana de contratos de cultivo y el Tribunal de garantías constitucionales en la Segunda República», VV.AA., La democracia constitucional. Estudios en homenaje al Profesor Francisco Rubio Llorente, CEPC, Madrid, 2002.

Pitarch, I., L'estructura del Parlament de Catalunya i les seves funcions politiques, 1932 1939, Curial, Barcelona, 1977.

Rejsek Pagés, J., La autonomía política de Cataluña: orígenes competencias y organización de la Generalidad, Departamento de la Presidencia, Barcelona, 1996.

7. Los sucesos del 6 de octubre de 1934 y la suspensión de la autonomía catalana

AZAÑa, M., Mi rebelión en Barcelona, Espasa-Calpe, Madrid, 1935.

Berges, C., Explicación de octubre, Madrid, 1935.

De Angulo, E., Diez Horas de Estat Catalá, Encuentro, Madrid, 2005.

Escofet Alsina F., De una derrota a una victoria: 6 de octubre de 1934-19 de julio de 1936, Argos Vergara, Barcelona, 1984.

NIN, A., «Los acontecimientos de octubre en Barcelona», Leviatán, n. ${ }^{\circ} 18$ (octubre-noviembre) 1935 .

\section{La Guerra Civil}

BAlCElls, A., «La Guerra Civil española y el autogobierno de Cataluña», en Cuatro estudios de historia de Cataluña (siglos XIX y XX), Universidad Pontificia de Salamanca, Salamanca, 1988.

UNED. Teoría y Realidad Constitucional, núm. 37, 2016, pp. 607-626 
Benavides, M. D., Guerra y revolución en Cataluña, Roca, México, 1978.

Castilla Latorre, J., Así cayó Cataluña, Edicions do Castro, A Coruña, 1988.

Dalmau Olivé, J., Nacionalismo catalá i Guerra Civil a Catalunya (1936-1939), Rafael Dalmau, Barcelona, 2002.

Pernau, J., Diario de la caída de Cataluña, Ediciones B, Barcelona, 1989.

Pi Sunyer, C., La República i la Guerra Civil. Memorias de un político catalán, Oasis, México, 1975.

Reverte, J. M., La caída de Cataluña, Crítica, Barcelona, 2006.

Rojas, C., La guerra en Cataluña, Plaza \& Janés, Esplugas de Llobregat, 1979.

Solé y Sabaté, J. M.; Villarroya, J. y Voltas, E., La Guerra civil a Catalunya (19361939), 4 vols. Edicions 62, Barcelona, 2005.

\section{La dictadura franquista}

Benet, J., Cataluña bajo el régimen franquista: informe sobre la persecución de la lengua y la cultura catalana por el régimen de Franco (1. a parte), Blume, Barcelona, 1979.

Colomer, J. M.; Ainaud de Lasarte, J. M. y Riquer i Permanyer, B., de, El anys del franquismo, Dopesa, Barcelona, 1978.

Colomines, J., Crònica de l'antifranquisme a Catalunya: apunt de memoria, Angle, Barcelona, 2003.

Cucurull, F., L'autodeterminació de Catalunya, Tibidabo, Barcelona, 1991.

Díez Esculies, D., L'oposició catalanista al franquismo: el republicanismo liberal i la nova oposició, 1939-1960, Publicacions de l'Abadia de Monserrat, Barcelona, 1996.

Fabre, J.; Huertas, J. M. y Ribas, A., Vint anys de resistencia catalana al franquismo, 1939-1959, La Magrana, Barcelona, 1978.

Ferré, M., La Generalitat de Catalunya a l'exili, Aymà, Barcelona, 1977.

Guibernau, M., Le nacionalisme catalá. Franquismo, transició i democracia, Pòrtic, Barcelona, 2002.

Johnston, H., Tales of nationalism: Catalonia, 1939-1979, Rutgers University Presss, New Brunswick/New Jersey, 1991.

Marín, M., Catalanisme, clientelisme i franquisme. Josep Maria de Porcioles, Societat Catalana d'Estudis Histórics/Institut d'Estudis Catalans, Barcelona, 2000.

Molinero, C. y Ysás, P., Catalunya durant el franquismo, Empúries, Barcelona, 1999.

PAGÈs I BLANCH, P. (dir.), Franquisme y repressio: la repressió franquista als països catalans, Universidad de Valencia, Valencia, 2004.

Pérez Andujar, J., Catalanes todos: las 15 visitas de Franco a Cataluña, Ediciones de la Tempestad, Barcelona, 2002.

RierA, I., Els catalans de Franco, Plaza \& Janés, Barcelona, 1998.

SALA, A., Crítica de la izquierda autoritaria en Cataluña: 1967-1974, Ruedo Ibérico, París, 1975.

SantaCana, C., El franquisme i els catalans. Els informes del Consejo Nacional del Movimiento (1962-1971), Afers, Catarroja, 2000.

Solé i Sabaté, J. M., La represió franquista a Catalunya, 1938-1953,

THOMAS, J. M., Falange, Guerra Civil i franquismo. FET y de las JONS de Barcelona en els primers anys del règim franquista, Publicacions de l'Abadia de Monserrat, Barcelona, 1992. 


\section{La «transición catalana»}

Aracil, R. y Segura A. (eds.), Memoria de la transició a Espanya i a Catalunya, 4 vols., Edicions Universitàries de Barcelona, Barcelona, 2000.

Arbós, X., «Los antecedentes históricos de la autonomía de Cataluña», Derecho Público de Cataluña, Barceló, M. y Vintró, J. (coords.), Atelier, Barcelona, 2008.

Benet, J., «Precedentes históricos del Estatuto», Comentarios sobre el Estatuto de Autonomía de Cataluña, vol. I, IEA, Barcelona, 1990.

BERNARD I RICART, R., «L'Assemblea de Catalunya (1971-1982): catalanisme popular i antifranquisme», Butlletí de la Societat Catalana d'Estudis Històrics, n. ${ }^{\circ}$ 13, 2002.

Boadella, A. et alii, Memoria de la transició a Espanya i a Catalunya. III, La reforma de l'exèrcit i de l'administració local, Aracil, R. y Segura, A. (eds.), Edicions de la Universitat de Barcelona, Barcelona, 2002.

GonzÁlez Casanova, J. A., "Cataluña en la gestación constituyente del Estado de las Comunidades Autónomas», Revista de Política Comparada, n. ${ }^{\circ} 4,1981$.

Lorés, J., La transició a Catalunya, 1973-1984. El pujolisme i els altres, Empùries, Barcelona, 1985.

Mascarell, F. y Manito, F. (ed.), Catalunya, 1973-1983. De la dictadura a la democràcia. Política, societat, economia, treball, cultura, oci, L'Avent, Barcelona, 1983.

SÁnchez Terán, S., De Franco a la Generalitat, Planeta, Barcelona, 1988.

SEllarés, M., "CDC i l'Assemblea de Catalunya, 25 anys després», L'Avenç : Revista de bistòria i cultura, n. ${ }^{\circ}$ 208, 1996.

Sobrequés I CALlicó, J., La fi del silenci: la recuperació de la Generalitat i el retorn de Tarradellas, Base, Barcelona, 2. ${ }^{\text {e ed., } 2002 .}$

- Catalunya i l'estatut d'Autonomía: el marc històric de l'autonomia de Cataluña, Undarius, Barcelona, 1976.

Tarradellas, J., "Ja soc aquí» Recuerdo de un retorno, trad. de Alfons Sureda i Carrión, Planeta, Barcelona, 1990.

Tarradellas, J. y Sobrequés i Callicó, J., Qué es la Generalitat de Catalunya, La Gaya Ciencia, Barcelona, 1976.

VV.AA., Memoria de Cataluña. Del regreso de Tarradellas hace 20 años al pacto Pujol-Aznar, El País, Barcelona, 1997.

\section{El restablecimiento provisional de la autonomía}

Huguet i Reverter, J. M.a: «Notes sobre el financament de l'Estatut de Catalunya en el període transitori», Jornades sobre l'Estatut 'Autonomia de Catalunya, Academia de Jurisprudencia y Legislació de Catalunya, Barcelona, 1980.

Molas, I., «El proceso de restablecimiento de la Generalidad de Cataluña», Federalismo y regionalismo, G. Trujillo Fernández (dir,), Centro de Estudios Políticos y Constitucionales, Madrid, 1979.

SEGURA I MAS, «L'Estatut, la reorganització autonómica de l'Estat i el context històric», Idees. N. ${ }^{\circ}$ monográfico sobre los Vint anys de l'Estatut d'autonomia de Catalunya, balanç i perspectiva, (octubre/diciembre), 1999. 
VV.AA., Regímenes preautonómicos y disposiciones complementarias: Cataluña, País Vasco, Galicia, Aragón, País Valenciano, Andalucía, Baleares, Extremadura, Castilla y León, Asturias, Murcia, Castilla-La Mancha, prólogo de Manuel Clavero Arévalo, Servicio Central de Publicaciones. Presidencia del Gobierno, Madrid, 1978.

\section{El Estatuto de Sau}

Gerpe Landín, M. et alii, Comentaris jurídics a l'Estatut d'Autonomia de Catalunya, Edicions 62, Barcelona, 1982.

GonzÁlez Casanova, J. A., «L’Estatut en la prespectiva del catalanisme politic», Taula de Canví.

Hortalá Arau, J., «El Estatuto de Cataluña de 1979: ámbito competencial», La España de la Autonomías, Espasa-Calpe, vol. II, Madrid, 1985.

Mariñas Otero, G. (dir.), El Estatuto de Autonomía de Cataluña de 18 de diciembre de 1979, UCM. Facultad de Ciencias Políticas y Sociología, Madrid, 1984.

Molas, I., Comentarís juridics a l'Estatut d'autonomía de Catalunya, Barcelona, 1982.

SÁnchez Terán, S. y Riera, S., L'Estatut d'Autonomia de Catalunya. Bases documentals per l'estudi del procés polític d'elaboració de l'Estatut de 1979, 4 vols. Edicions 62, Barcelona, 1982.

Santamaria Pastor, J. (ed.), Estatuto de Autonomía de Cataluña. Trabajos parlamentarios, Publicaciones del Congreso de Diputados, Madrid, 1985.

Sobrequés i Callicó, J., El estatuto de autonomía de Cataluña, Undarius, Barcelona, 1977.

VV.AA., Comentarios sobre el Estatuto de Autonomía de Cataluña, Institut de Estudios Autòmics, Barcelona, 1990.

- Comentaris sobre l'Estatut d'Autonomia, 3 vols., Institut d'Estudis Autonòmics/ Facultat de Dret de la Universitat de Barcelona/ Facultat de Dret de la Universitat Autónoma de Barcelona, Barcelona, 1988.

- Estudi juridic de l'Estatut d'Autonomia de Catalunya, Universidad de Barcelona, Barcelona, 1981.

Jornades sobre l'Estatut d'Autonomía de Catalunya, Academia de Jurisprudencia i Legislació de Catalunya, Barcelona, 1980.

\section{El desarrollo de las previsiones de la Constitución española de 1978}

AjA, Fernández, E., «Les relacions entre la Generalitat i l'Estat», en Vint-i-cinc anys d'Estatut d'autonomia de Catalunya: balanç y perspectives, Institut d'Estudis Autonòmics, Barcelona, 2005.

Alberti Rovira, E., «L'Estatut d'autonomia en el marc de la Constitució», en Vint-i-cinc anys d'Estatut d'autonomia de Catalunya: balanç y perspectives, Institut dd'Estudis Autonòmics, Barcelona, 2005.

Argullol, E., Desarrollar el autogobierno, Península, Barcelona, 2002.

Basset, Ll.; Culla, J. B. y Riquer, B. (eds.), Memoria de Catalunya. Del retorn de Tarradellas al Pacte Pujol-Aznar, Taurus, Madrid/Barcelona, 1997. 
Bayona Rocamora, A., «La delimitación de competéncies de Catalunya i el traspàs de serveis», Vint-i-cinc anys d'Estatut d'autonomia de Catalunya: balanç y perspectives, Institut dd'Estudis Autonòmics, Barcelona, 2005.

CAstells, A., «Catalunya i l'Estat espanyol en la prespectiva de l'Estat autonòmic», Ll. Armet et alii, Federalisme $i$ Estat de les autonomies, Edicions 62, Barcelona, 1988.

Esteve I ABAD, P. et alii, Catalunya vint anys d'Estatut: Autonomia o sobirania?: Conferences impartides els mesos de gener i febrer de 1999, en el Seminari coordinat per Josep Serrano Daura, Universitat Internacional de Catalunya, Curs acadèmic 1998/1999, Universitat Internacional de Catalauña, Barcelona, 1999.

Freixes Sanjú́N, T., «Drets fonamentals dels catalans», en Comentaris sobre l'Estatut d'Autonomia de Catalunya, Institut d'Estudis Autonòmics, vol. I, Barcelona, 1998.

GonZÁlez CASANOvA, J. A., «Cataluña, paradigma del sistema autonómico español», Cuenta y Razón, n. ${ }^{\circ}$ 30, 1987.

LóPez Medel, J., El Estatuto de Cataluña como instrumento jurídico: una meditación sobre España. Fragua, Madrid, 2006.

Nel.Lo i Colom, O. (dir.), Deu anys d'ajuntaments democràtics (1979-1989): elements per a un balanç, Federació de Municipis de Catalunya, Barcelona, 1989.

Pujol, J., Desde la Constitución hasta hoy, Generalitat de Cataluña, Barcelona, 2003.

Ridao i Martin, J., De l'autonomia a la sobirania: estratègies d'impuls de l'autogovern, Mediterrània, Barcelona, 2003.

Tornos MAs, J. «Las competencias de la Generalitat en el Estatuto de Cataluña», Revista de Estudios de Vida Local, n. ${ }^{\circ} 205$ (enero-marzo), 1980.

VIDAL-QuAdRAS, A., La Constitución traicionada: de la imagen de la Transición a la embestida secesionista, Libros Llibres, Madrid, 2006.

Vila i Lusilla, A. (coord.), Catalunya, 20 anys d'autonomia (1980-2000), Generalitat de Catalunya, Barcelona, 2000.

VV.AA., Vint-i-cinc anys d'Estatut d'Autonomia de Catalunya: balanç i perspectives, Instituto d'Estudis Autonòmics, Barcelona, 2005.

Vint-i-cinc anys d'Estatut: 1979-2004. Jornades amb motiu del 25é aniversari de l'Estatut d'Autonomia de Catalunya, 1. ${ }^{\text {a }}$ ed., Parlament de Catalunya, Barcelona, 2005.

La Autonomía de Catalunya, Universidad Internacional Menéndez Pelayo, Madrid, 1982.

14. Una nueva etapa para Cataluña, el Estatuto de Autonomía de 2006, la Sentencia del TC de 2010 y el llamado proceso soberanista

a) El camino previo a la reforma, diferentes propuestas

Aguiar de Luque, Luis [et al.]. La justicia ante la reforma de los Estatutos de Autonomía. Cizur Menor (Navarra): Aranzadi, 2005.

Aguilar Fontalba, José. «Poder judicial y administración de justicia en la propuesta del nuevo Estatuto para Cataluña». En: Repertorio Aranzadi del Tribunal Constitucional. N. ${ }^{\circ} 18$ (2005).

AJA, E., «La proposición de reforma del Estatuto de Cataluña», Revista Aragonesa de Administración Pública. Núm- monográfico «De la reforma estatutaria», 2005.

UNED. Teoría y Realidad Constitucional, núm. 37, 2016, pp. 607-626 
Alberti Rovira, E., «Cataluña. El proceso de reforma del Estatuto de autonomía de Catalunya», Modelo de Estado y reforma de los Estatutos, V. Garrido Mayol (dir.), Fundacón Profesor Manuel Broseta, Valencia, 2007.

Alonso Perelló, L., L'Estatut és de tothom: el procés participatiu per a la reforma de l'Estatut d'autonomia de Catalunya. Barcelona: Generalitat de Catalunya. Departament de Relacions Institucionals i Participació, 2006. Vol. 1.

Àlvarez CONDE, E.,. «La vía catalana de reforma estatutaria». En: Reforma constitucional y reformas estatutarias. Madrid: Iustel, 2007.

Álvarez JunCO, J., «España plural, Cataluña plural», Claves de Razón Práctica. N. ${ }^{\circ} 159$, ene.-feb. 2006.

Aparicio, Miguel A. «L'adequació de l'estructura de l'Estat a la Constitució (reforma constitucional vs. reforma dels estatuts)». En: Revista Catalana de Dret Públic. N. ${ }^{\circ}$ 31, 2005.

Aparicio, M. Á., "L'autonomia de Catalunya i l'evolució de l'Estatut autonòmic», en Vint-icinc anys d'Estatut d'autonomia de Catalunya: balanç y perspectives, Institut dd'Estudis Autonòmics, Barcelona, 2005.

Balaguer Callejón, Francisco. «Reformas estatutarias y reconocimiento de derechos», Revista General de Derecho Constitucional. N. ${ }^{\circ} 3$ (2007).

Borrell Mestre, JoAquim. «Justicia y Comunidades Autónomas: las modificaciones que se tramitan en el Congreso de los Diputados. Especial referencia al proyecto de reforma del Estatuto de autonomía de Cataluña«. En: Revista Española de la Función Consultiva. N. ${ }^{\circ} 4$ jul.-dic. 2005.

Cabellos Espiérrez, M. Á., "Crónicas sobre el actual proceso de reforma de los Estatutos de Autonomía: Catalunya», Revista General de Derecho Constitucional, n. ${ }^{\circ}$, 2006.

Carod-Rovira, J. L., La Nova Catalunya, Ediciones, 62, Barcelona, 2003.

Carreras Serra, F., «Cataluña. El proyecto de nuevo Estatuto de Cataluña», en Modelo de Estado y reforma de los Estatutos, V. Garrido Mayol (dir.), Fundación Profesor Manuel Broseta, Valencia, 2007.

- «Reflexiones sobre la propuesta de nuevo Estatuto de Cataluña», Teoría y Realidad Constitucional, n. ${ }^{\circ}$ 16, 2005.

Colino, C. «Constitutional change without constitutional reform: Spanish federalism and the revision of Catalonia's Statute of Autonomy. En: Publius: the journal of federalism. Vol. 39, N. 2 (spring 2009), pp. 262-288.

Corretja i Torrens, Mercè. «La reforma del Estatuto de autonomía de Cataluña». En: La reforma del Estado autonómico. Madrid: Centro de Estudios Políticos y Constitucionales, 2005.

Del Burgo, J. I., Jacque a la Constitución: de la propuesta soberanista de CIU al federalismo asimétrico de Maragall, Ediciones Académicas, Madrid, 2003.

Dictamen 269/2005. Sobre la propuesta de proposición de Ley orgánica por la que se establece el Estatuto de autonomía de Cataluña y se deroga la Ley orgánica 4/1979, de 18 de diciembre, del Estatuto de autonomía de Cataluña, las enmiendas y votos particulares reservados para defender en el Pleno: Consejo Consultivo de la Generalitat de Cataluña», Revista Española de la Función Consultiva. n 7, 2007.

ForN, I., El tripartit vist desde Madrid, Roca, Barcelona, 2004.

GabAncho, P., La batalla de l'Estatut, Empuries, Barcelona, 2006. 
García Torres, J; «Los derechos estatutarios en la propuesta catalana de reforma», en El estado autonómico: Actas de las XI Jornadas de la Asociación de Letrados del Tribunal Constitucional, Madrid, Centro de Estudios Políticos y Constitucionales, Col-lecció «Cuadernos y Debates», n. ${ }^{\circ}$ 170, 2006.

Gerpe Landín, Manuel; Cabellos Espiérrez, Miguel Àngel; Fernández de Frutos, MarTa. «El Tribunal Superior de Justicia de Cataluña. Una propuesta de reforma de sus competencias», Revista Jurídica de Catalunya. N. 3 (2005).

INFORME de l'Institut d'Estudis Catalans al Parlament de Catalunya sobre la reforma de l'Estatut, Barcelona: IEC, 2004.

González Casanova, J. A., Escrits de combat pel triomf de l'esquerra (2001-2004), Mediterránea, Barcelona, 2005.

GoNZÁLEZ SOLER, O. E., «El procedimiento legislativo adecuado para la reforma del Estatuto de Cataluña», Repertorio Aranzadi del Tribunal Constitucional, núm, 4, 2006.

INFORME sobre la reforma de l'Estatut, Institut d'Estudis Autonòmics de la Generalitat, Barcelona, 2004.

Institut d'Estudis Autonòmics de la Generalitat, Barcelona, 2003.

Jiménez Asensio, R., «Reforma del Estatuto de Cataluña y ampliación de competencias», Revista Vasca de Administración Pública, n. ${ }^{\circ}$ 70, 2004.

MAdre, M. DE LA e ICETA, M., El Estatuto de Cataluña: una propuesta para el acuerdo, Mediterranea, Barcelona, 2005.

Madrid Delgado, M., «El Plan Maragall o el error Zapatero», Temas para el debate, n. ${ }^{\circ} 132$ (noviembre), 2005.

Maragall, P., Una propuesta catalana para la España plural, Entitat Autónoma del Diari Oficial i de Publicacions, Barcelona, 2004.

Marcet, J. y SAntamaría Ossorio, J., «18-j: el referéndum del nuevo Estatuto de Cataluña», Claves de la Razón Práctica, n. ${ }^{\circ}$ 165, 2006.

Marsal, Marc. «Recensió jurisprudencial sobre la reforma de l'Estatut d'autonomia de Catalunya». En: Revista Catalana de Dret Públic. N.o 31 (des. 2005).

Montilla Martos, José ANTONio. «Apuntes sobre colaboración y participación en el estado autonómico. A propósito de la propuesta de reforma del Estatuto de Cataluña», En: Revista d'Estudis Autonòmics i Federals. N. ${ }^{\circ} 1,2005$.

Pemán Gavín, JuAn María. «Sobre los límites de las reformas estatutarias: derechos históricos y estado de las Autonomías. A propósito de la propuesta de nuevo Estatuto aprobada por el Parlamento de Cataluña». En: Revista General de Derecho Administrativo. n. ${ }^{\circ}$ 12, 2006.

Pérez Royo, J. y Carrasco Durán, M., «Regulación en el Estatuto de Cataluña de la participación de la Generalidad en las instituciones y políticas estatales», en Estudios sobre la reforma del Estatuto, Institut d'Estudis Autonòmics, Barcelona, 2004.

Pérez Royo, J. y Medina Guerrero, M., «Estudio sobre las disposiciones fiscales en la reforma del Estauto de Cataluña», en Estudios sobre la reforma del Estatuto, Institut d'Estudis Autonòmics, Barcelona, 2004.

Pérez Tremps, P., «La acción exterior y la participación europea ante una posible reforma del Estatuto de Cataluña», en Estudios sobre la reforma del Estatuto, Institut d'Estudis Autonòmics, Barcelona, 2004.

Quadra-Salcedo Janini, T. DE., «Después del referéndum de Cataluña», Claves de la Razón Práctica, n. 164 (agosto), 2006.

UNED. Teoría y Realidad Constitucional, núm. 37, 2016, pp. 607-626 
RoIG MolÈs, E., «La reforma del Estado de las autonomías. ¿Ruptura o consolidación del modelo Constitucional de 1978?», Revista d'Estudis Autonòmics i Federals, n. ${ }^{\circ} 3$, 2006.

SOLOZÁBAL ECHAVARria, JUAN JosÉ. «Sobre las reformas estatutarias y la propuesta del Parlamento catalán». En: La reforma de los estatutos de autonomía: actas del IV Congreso Nacional de la Asociación de Constitucionalistas de España. Valencia: Tirant lo Blanch, 2006.

Viver I PI-Sunyer, C., «La reforma del Estatuto de Autonomía de Cataluaña», Reformas territoriales, 2006.

Viver Pi-Sunyer, CARles. «Grandes reformas o pequeños pasos?: una perspectiva desde Cataluña «. La reforma del estado autonómico español y del estado federal alemán. Madrid: Centro de Estudios Políticos y Constitucionales, 2009.

Xiol Ríos, J. A., «Evaluación de los aspectos relacionados con la Administración de justicia en una futura reforma del Estatuto de Autonomía de Cataluña», en Estudios sobre la reforma del Estatuto, Institut d'Estudis Autonòmics, Barcelona, 2004.

b) El Estatuto de Autonomía de 2006, la Sentencia de 2010 y el «proceso soberanista»

Aguado Renedo, C., "Sobre un eventual referéndum consultivo en el proceso soberanista catalán», Cuadernos de Alzate, n. ${ }^{\circ}$ 46-47, 2013.

Alberti Rovira, E., «El Estado de las Autonomías después de la Sentencia del Tribunal Constitucional sobre el Estatuto de Cataluña», n. ${ }^{\circ} 25$ monográfico de El Cronista del Estado Social y Democrático de Derecho, 2010.

Aláez Corral, B., en «Constitucionalizar la secesión para armonizar la legalidad constitucional y el principio democrático en Estados territorialmente descentralizados como España», Revista d'Estudis Autonòmics i Federals, IEA, n. ${ }^{\circ}$ 22, 2015.

Albertí Rovira, E., «La participació de les comunitats autònomes en institucions de l'Estat en els nous estatuts d'autonomia», Revista Activitat Parlamentària, n. ${ }^{\circ} 15$, 2008.

«El blindatge de les competències i la reforma estatutària», Revista catalana de Dret Public, n. ${ }^{\circ} 31,2005$.

Álvarez Conde, E., Tur Ausina, R., «El Estatuto de Cataluña a través de los votos particulares a la STC 31/2010», Teoría y Realidad Constitucional, n. ${ }^{\circ}$ 28, 2011.

Alzaga Villaamil., O., «La Nación como Poder Constituyente en los preámbulos de las leges superiores. El Estatut de 2006 y la STC 31/2010», Teoría y Realidad Constitucional, n. ${ }^{\circ} 28,2011$.

Aparico PÉrez, M. Á., «Protecció de l'autogovern i control d'estatutarietat: El Consell de Garantìes Estatutaries», Revista catalana de dret public, n. ${ }^{\circ}$ 39, 2009.

Aparicio Wilhelmi, Marco; Jaria, Jordi; Pisarello, Gerardo. «Los derechos y principios del ámbito civil y social en el Estatuto de autonomía de Cataluña». En: Derechos y principios rectores en los estatutos de autonomía. Barcelona: Atelier, 2008.

Arias Abellán, M. a . D., «La ordenación jurídica de los recursos financieros en el Estatuto de Autonomía de Cataluña», Revista d'Estudis Autonòmics i Federals, n. ${ }^{\circ}$ 6, 2008.

Ariño Ortiz, G., La independencia de Cataluña. Historia, Economía, Política y Derecho, Thomson Reuters Aranzadi, Cizur Menor —Navarra-, 2015. 
Balaguer Callejón, F., «Las cuestiones institucionales en la STC 31/2010, de 28 de junio», n. ${ }^{\circ} 25$ monográfico de El Cronista del Estado Social y Democrático de Derecho, 2010.

Balaguer Callejón, María Luisa. »Reformas estatutarias y reconocimiento de derechos». En: Revista General de Derecho Constitucional. N. 3 (abr. 2007), 22 p;

Barceló i Serramalera, M., «Las declaraciones de derechos y deberes estatutarias: especial referencia al Estatuto de Autonomía de Catalunya», en Nuevos Estatutos y reforma del Estado: las experiencias de España e Italia a debate, Castellá Andreu, J. y Olivertti, M. (coords.), Atelier, Barcelona, 2009.

Barceló M., Corretja M., González Bondia A., López J. y Vilajonasa J.M., «El derecho a decidir. Teoría y práctica de un nuevo derecho», Atelier, Barcelona, 2015.

Bayona i Rocamora, A.; Ferreres, Víctor. «El Tribunal Constitucional davant l'Estatut». En: Revista Catalana de dret public. Especial Sentència 31/2010 del Tribunal Constitucional, sobre l'Estatut d'Autonomia de Catalunya de 2006, diciembre 2010.

Blanco Valdés, R., «Constitución, descentralización, federalismo: ¿Qué se puede aprender de la experiencia española?», en el libro colectivo El Estado autonómico in fieri. La reforma de los Estatutos de Autonomía (coordinador: M.J. TEROL BECERRA), Instituto Andaluz de Administración Pública, Sevilla, 2005.

Blanco VAldÉs, R., «Encuesta sobre la STC 31/2010», Teoría y Realidad Constitucional, n. ${ }^{\circ} 28,2011$.

Bossacoma i Busquets, P., Justícia i legalitat de la secessió. Una teoria de l'autodeterminació nacional des de Catalunya, Institut d'Estudis Autonòmics, 2015.

Buchanan, A., «Self - Determination and the Right to Secede», Journal of International Affairs, Vol. 45, no 2, 1992.

Justice, Legitimacy, and Self-Determination: Moral Foun- dations for International Law, Oxford University Press, Oxford, 2004.

Canmaño Domínguez, F., «Sí, pueden (Declaraciones de derechos y Estatutos de Autonomía)», Revista española de Derecho Constitucional, n. ${ }^{\circ}$ 79, 2007.

CaAmaño, F., «Democracia federal. Apuntes sobre España», Madrid. 2014

Caminal Badia, M. «La reforma dels estatuts i la llengua catalana», Revista de Llengua i Dret, n. ${ }^{\circ} 47,2007$.

CAnosa Usera, R., «Encuesta sobre la STC 31/2010», Teoría y Realidad Constitucional, n. ${ }^{\circ} 28,2011$.

Carrillo López, M., «Después de la sentencia, un Estatuto desactivado», n. 25 monográfico de El Cronista del Estado Social y Democrático de Derecho, 2010.

- «Los derechos, un contenido constitucional de los Estatutos de autonomía». En: Revista Española de Derecho Constitucional. N. ${ }^{\circ} 80$ (mayo-agosto 2007.

—Encuesta sobre la STC 31/2010», Teoría y Realidad Constitucional, n. ${ }^{\circ}$ 28, 2011.

Carrillo López M. (dir.); López Bofill, H., y Torres, A., L'Estatut d'Autonomia de Catalunya de 2006. Textos jurídics, Institut d'Estudis Autonòmics, Barcelona, 2006.

CASTEllà ANDreu, J.M., «La secesión catalana, entre la política y el derecho», en Anuario de la Facultad de Derecho de la Universidad de Alcalá, vol. VII, 2014.

Castellà Andreu, J. M. (coord.); Expósito Gómez, E. y Martín NúÑez, E., «Els drets davant l'Administració i les seves garanties en l'Estatut d'Autonomia de Catalunya», Col.lecció Estudis. Escola d'Administració Pública de Catalunya, n. ${ }^{\circ}$ 28, Barcelona, 2007.

UNED. Teoría y Realidad Constitucional, núm. 37, 2016, pp. 607-626 
Chacon, C., y Ruiz Robledo, A., «Comentario del Dictamen del Tribunal Supremo canadiense de 20 de agosto de 1998 sobre la secesión de Quebec» en Teoría y Realidad Constitucional, n. ${ }^{\circ}$ 3, 1999.

Corcuera AtienZA, J., «Encuesta sobre la STC 31/2010», Teoría y Realidad Constitucional, n. ${ }^{\circ} 28,2011$.

Corretja i Torrens, M. y Viver Pi-Sunyer, C., «El nou disseny competencial en matèria de funció pública i règim jurídic de les administracions públiques catalanes», La distribució de competències en el nou Estatut. Col.lecció IEA. Institut d'Estudis Autonòmics, n. ${ }^{\circ}$ 52, 2007.

«La participació de la Generalitat en l'exercici de competències estatals a l'Estatut de 2006: les infraestructures del transport», Revista d'Estudis Autonòmics i Federals, n. ${ }^{\circ}$ 5, 2007.

«La projecció supraterritorial de la llengua catalana en el nou Estatut d'autonomia de Catalunya», Revista de Llengua i Dret, n. ${ }^{\circ}$ 47, 2007.

«L'Estatut d'Autonomia de 2006. Aspectes territorials», Anuari Territorial 2006. Societat Catalana d'Ordenació del Territori. Institut d'Estudis Catalans, 2007.

— «a reforma de l'Estatut d'Autonomia i les competències de la Generalitat», Revista Activitat Parlamentària, n. ${ }^{\circ} 7$ (enero), 2005.

De Carreras Serra, F., «Encuesta sobre la STC 31/2010», Teoría y Realidad Constitucional, n. ${ }^{\circ} 28,2011$.

De Esteban, J., «Reflexiones en torno al voto particular de Javier Delgado», n. ${ }^{\circ} 25$ monográfico de El Cronista del Estado Social y Democrático de Derecho, 2010.

De la QuAdra-SAlCEdo Janini, T., «El modelo competencial en la STC 31/2010, de 28 de junio», n. ${ }^{\circ} 25$ monográfico de El Cronista del Estado Social y Democrático de Derecho, 2010.

- «Interpretación y determinación del alcance de las competencias constitucionalmente reservadas al Estado», Revista para el Análisis del Derecho Inndret, julio, 2009.

Diez-Revorio, J., «Proceso constituyente y proceso descentralizador: ¿de dónde venimos y a dónde vamos?, en El Futuro Territorial del Estado Español, Oliver Araujo, J. (Dr.), Tirant lo Blanch, Valencia, 2014.

EsPaDA, A., Informe sobre la decadencia de Cataluña reflejada en su Estatuto, Espasa, Madrid, 2006.

Expósito, E., «La regulación de los derechos de los nuevos estatutos de autonomía», Revista d'Estudis Autonòmics i Federals, n. ${ }^{\circ}$ 5, 2007.

Fernández FArreres, G., «Las competencias de Cataluña tras la Sentencia del Tribunal Constitucional sobre el Estatut», n. 25 monográfico de El Cronista del Estado Social y Democrático de Derecho, 2010.

—El Estatuto de Cataluña y la reforma del Estado», Repertorio Aranzadi del Tribunal Constitucional, n. ${ }^{\circ} 18,2006$.

Ferreres Comella, V.; Biglino Campos, P. y Carrillo, M., Derechos, deberes y principios en el nuevo Estatuto de Autonomía de Cataluña, Centro de Estudios Políticos Constitucionales, Madrid, 2006.

Fondevila Marón, M., «Derecho a decidir y soberanía. A propósito de la STC 42/2014» en Teoría y Realidad Constitucional, n. ${ }^{\circ}$ 34, 2014. 
Fossas Espalder, E., «Interpretar la política. Comentario a la STC 42/2014, de 25 de marzo, sobre Declaración de soberanía y el derecho a decidir del pueblo de Cataluña», Revista Española de Derecho Constitucional, n. ${ }^{\circ} 101,2014$, pp. 273-300.

«El Estatuto tras la sentencia», Teoría y Realidad Constitucional, n. ${ }^{\circ}$ 27, 2011.

García i Mengual, F; «La Constitucionalidad de la propuesta de la reforma del Estatuto de autonomía de Cataluña: consideraciones del Consell Consultiu de la Generalitat», Revista Española de la Función Consultiva, n. ${ }^{\circ}$ 4, 2006

García RocA, J., «De las competencias en el Estatuto de Cataluña según la STC 31/2010, de 28 de junio: una primera lectura integradora», n. ${ }^{\circ} 25$ monográfico de El Cronista del Estado Social y Democrático de Derecho, 2010.

García Roca, J. (y otros), en Pautas para una reforma constitucional. Informe para el debate, Thomson Reuter Aranzadi, 2014

- «Reforma constitucional en clave federal?», en El Cronista del Estado Social y Democrático de Derecho, n. ${ }^{\circ} 34,2013$.

— «Encuesta sobre la STC 31/2010», Teoría y Realidad Constitucional, n. ${ }^{\circ}$ 28, 2011.

García-Moncó, A., «Paisaje después de una sentencia: la penúltima reforma de la financiación autonómica», n. ${ }^{\circ} 25$ monográfico de El Cronista del Estado

Gavara de Cara, J.C., «Los efectos de la STC 31/2010», Teoría y Realidad Constitucional, n. ${ }^{\circ} 27,2011$.

Jiménez AsEnsio, R., «Reforma del Estatuto de Cataluña y ampliación de competencias», Revista Vasca de Administración Pública, n. ${ }^{\circ}$ 70, 2004.

Keating, Naciones contra el estado: el nacionalismo de Cataluña, Quebec y Escocia. Barcelona: Ariel, 1996.

Koskenniemi, M., «National Self - Determination Today: Problems of Legal Theory and Practice», International and Comparative Law Quarterly, Vol. 43, n. 2. ${ }^{\circ}, 1994$.

López Aguilar, J.F., «La sentencia más larga. Repercusiones de la STC 31/2010», Teoría y Realidad Constitucional, n. ${ }^{\circ}$ 27, 2011.

LOPEZ BASAguren, A., «Escocia y el referéndum por la independencia: algunas enseñanzas» Cuadernos de Alzate, n. ${ }^{\circ}$ 46-47, 2013, pp. 127 a 141.

López-Medel BAscones, J., El Estatuto de Cataluña como instrumento jurídico: una meditación sobre España, Fragua, Madrid, 2006.

Lucas Murillo de la Cueva, P., «La forma y la permanencia del Estado. (Observaciones sobre la organización territorial del poder político)», Anuario Parlamento y Constitución, n. ${ }^{\circ}$ 15, 2012-2013.

Llorens, E., La autonomiá en la integración política: la autonomía en el Estdo moderno: El Estatuto de Cataluña: textos parlamentarios y legales, Reus, Madrid, 2008.

Marsal i Ferret, M., «Recensión jurisprudencial sobre la reforma del Estatuto de autonomía de Cataluña», Revista Catalana de Dret Públic, n. ${ }^{\circ} 31,2005$.

Martínez Calvo, J., Los límites de la nación y la reforma constitucional en España, Tirant lo Blanch, Valencia, 2015.

Medina Ortega, M., El derecho de secesión en la Unión Europea, Marcial Pons, Madrid 2014.

Méndez Elias, C., «Aproximación a la sentencia del Tribunal Constitucional sobre el Estatuto de Autonomía de Cataluña», Revista General de Derecho Constitucional, n. ${ }^{\circ} 10$ (octubre), 2010. 
MolinA, I., «Independentismo e integración europea: la imposible adhesión automática a la UE de un territorio secesionado», ARI Real Instituto Elcano, 2012.

MúÑoz Machado, S., «Dentro de los términos de la presente Constitución», n. ${ }^{\circ} 25$ monográfico de El Cronista del Estado Social y Democrático de Derecho, 2010.

"La reforma constitucional y Cataluña», en Cuadernos 15, Círculo Cívico de Opinión, marzo, 2015.

Ortega Alvarez, Luis, «La posición de los Estatutos de Autonomía con relación a las competencias estatales tras la Sentencia del Tribunal Constitucional 31/2010, de 28 de junio, sobre el Estatuto de Autonomía de Cataluña». Revista española de derecho constitucional. Vol. 30. n. ${ }^{\circ}$ 90, 2010.

—Els nous estatuts d'autonomia». Quaderns de Dret Local. N. ${ }^{\circ} 16$, febrer 2008.

PARejo Alfonso, L., «Encuesta sobre la STC 31/2010», Teoría y Realidad Constitucional, n. ${ }^{\circ} 28,2011$.

Pérez-Moneo, M., "Cataluña pivota sobre el Derecho a decidir», Revista General de Derecho Constitucional, n. ${ }^{\circ}$ 18, 2014.

Pulido Quecedo, M., «El Estatuto de Autonomía de Cataluña. Anotado con la Jurisprudencia sistematizada de la STC 31/2010, de 28 de junio.», Aranzadi, Thomson Reuters, Navarra 2010.

Quintana Ferrer, E., " La financiación de la Generalitat en el nuevo Estatuto de Autonomía de Cataluña », Nueva fiscalidad, n. ${ }^{\circ}$ 6, 2007.

Rebollo Puig, M., «Elogio de los Jueces», n. ${ }^{\circ} 25$ monográfico de El Cronista del Estado Social y Democrático de Derecho, 2010.

Ridao i Martín, J., Curs de dret públic de Catalunya. Comentari a l'Estatut. Ariel/Escola d'Administració Pública, Barcelona, 2007.

—La juridificación del derecho a decidir en España. La STC 42/2014 y el derecho a aspirar a un cambio político del orden constitucional», Revista de Derecho Político, n. ${ }^{\circ} 91,2014$.

Roig MolÈs, E., «La regulació de les relacions de la Generalitat amb l'Estat en el nou Estatut d'autonomia de Catalunya», Revista d'Activitat Parlamentària, n. ${ }^{\circ}$ 15, 2008.

Rodríguez Carbajo, J. A., «Los recursos de casación en la STC 31/2010 sobre el Estatuto de Autonomía de Cataluña», Actualidad Administrativa, n. ${ }^{\circ}$ 16, 2010.

Ruipérez Alamillo, J., «La nueva reivindicación de la secesión de Cataluña en el contexto normativo de la Constitución española de 1978 y el Tratado de Lisboa», Teoría y Realidad Constitucional, n. ${ }^{\circ}$ 31, 2013.

Ruiz-Rico Ruiz, G., Los límites constitucionales del Estado Autonómico, CEPC, Madrid, 2001.

Santolaya Machetti, P., «Posición del Consejo de Garantías Estatutarias de la Generalidad de Cataluña en el sistema institucional», Los órganos garantes de la autonomía politica: defensa institucional y protección de los derechos. Barcelona: Atelier, 2009.

Tajadura Tejada, J., «La sentencia del Tribunal Constitucional sobre el Estatuto de Cataluña», Temas para el debate, n. ${ }^{\circ} 189,2010$.

«El pronunciamiento del Tribunal Constitucional sobre el preámbulo del Estatuto de Autonomía de Cataluña», Teoría y Realidad Constitucional, n. . 27, 2011.

Tierney, S., «Legal Issues Surrounding the Referendum on Independence for Scotland», University of Edinburgh, School of Law, Research Paper, European Constitutional Law Review, vol. 9, 2013. 
Torres del Moral, A., «El Estado autonómico. Segunda fase», Reforma constitucional y reforma estatutaria. Vera Santos, J. M. y Díaz-Revorio, J. (coords.), La Ley, Madrid, 2009.

Tornos Mas, J., «El Estatuto de Autonomía de Cataluña, y el Estado Autonómico, tras la Sentencia del Tribunal Constitucional 31/2010», n. 25 monográfico de El Cronista del Estado Social y Democrático de Derecho, 2010.

- De Escocia a Cataluña. Referéndum y reforma constitucional, Iustel, Madrid, 2015.

«La nova configuració de les competències compartides a l'Estatut d'autonomia. Alguns problemes en la seva aplicació», en La distribució de competències en el nou Estatut. Col.lecció IEA. Institut d'Estudis Autonòmics, n. ${ }^{\circ}$ 52, 2007.

Torres Muro, I., Alvarez Rodriguez, I., «El Poder Judicial en Cataluña en la STC 31/2010», Teoría y Realidad Constitucional, n. ${ }^{\circ} 27,2011$.

Tudela Aranda, José. «La disposición adicional primera de la Constitución y los nuevos estatutos de autonomía. La historia como legitimación de la autonomía». En: Revista de administración pública. N. ${ }^{\circ} 173$, mayo-agosto 2007.

Tur Ausina, Rosario. Las consecuencias jurídicas de la Sentencia 31/2010, de 28 de junio del Tribunal Constitucional sobre el Estatuto de Cataluña: la sentencia de la perfecta libertad. Cizur Menor (Navarra): Aranzadi, 2010.

Urbiola Lopez de Montenegro, J., .El proceso de independencia de Kosovo Su incidencia en el principio de soberanía e integridad territorial del Estado, CEPC. Madrid, 2013.

Vidal-FolCh DE BALAnzó, X., ¿ Cataluña independiente? , Los Libros de la Catarata-Fundación Alternativas, Madrid, 2013.

Vintró Castells, J., Barceló Serramelera, M., Dret públic de Catalunya, Atelier, Barcelona, 2008.

Viver Pi-Sunyer, C., «El Estatuto de Cataluña en el marco de la Constitución», Las reformas estatutarias y la articulación territorial del Estado, XIV Jornadas de la Asociación Española de Letrados de Parlamentos, Tecnos, Madrid, 2008.

«La riforma dello Statuto della Comunità Autonoma di Catalogna: principali novità e problemi di costituzionalità», Revista Diritto e Societá, n. ${ }^{\circ}$ 3, 2008.

- «a riforma dello statuto della comunità autonoma di Catalogna: principali novità e problemi di costituzioonalità insorti», I cantieri del federalismo in Europa, Issirfa-Istituto di Studi sui Sistemi Regionali Federali e sulle Autonomie «Massimo Severo Giannini», Roma, 2008.

—Les competències de la Generalitat a l'Estaut 2006: Objectius, tènciques emprades, criteris d'interpretació i comparació amb els altres estatuts reformats», $L a$ distribució de competències en el nou Estatut. Col-lecció IEA. Institut d'Estudis Autonòmics, n. ${ }^{\circ}$ 52, 2007.

—En defensa dels estatuts d'autonomia com a normes jurídiques delimitadores de competències. Contribució a una polémica jurídico constitucional», Revista d'Estudis Autonòmics i Federals, n. ${ }^{\circ}$ 1, 2005.

Viver Pi-Sunyer, C., Barceló i Serramalera, M.; Riu Fortuny, R.; Tornos Mas, J. y Corretja i Torrens, M., La distribució de competències en el nou Estatut, Col.lecció IEA. Institut d'Estudis Autonòmics, n. ${ }^{\circ}$ 52, 2007.

Viver Pi-Sunyer, C., Balaguer Callejón, F. y Tajadura Tejada, J., «La reforma de los Estatutos de Autonomía: con especial referencia al caso de Cataluña», FORO, n. ${ }^{\circ} 2,2005$. 
VV.AA., «El Tribunal Constitucional y el Estatut», n. ${ }^{\circ} 25$ monográfico de El Cronista del Estado Social y Democrático de Derecho, 2010.

«El nou model de finançament autonòmic», Revista Catalana de Dret Públic, n. ${ }^{\circ} 32,2005$.

$* * *$

TITLE: Bibliographical repertoire

ABSTRACT: This bibliographical repertoire shows a long list of reference books and research papers in reviews about Cataluña. All of them are made from a multiple perspectives: historical, political and legal.

RESUMEN: Este repertorio de bibliografía muestra un extenso número de obras sobre Cataluña; una recopilación que se presenta con vocación histórica, politica y jurídica.

Key words: Cataluña, Autonomy, Secession.

Palabras Clave: Cataluña. Autonomía. Secesión.

FECHA DE RECEPCIÓN: 15.12.2015

FECHA DE ACEPTACión: 15.01.2016 